Боева А.В., Москвитина У.С.

\title{
Основные теоретические подходы к синдрому эмоционального вы-горания у врачей
}

Белгородский государственный национальный исследовательский университет (Россия, Белгород)

doi: $10.18411 / 1 j-05-2021-42$

\section{Аннотация}

В обзоре рассматриваются основные теоретические подходы к синдрому эмоционального выгорания. Большинство авторов полагают, что возникновение СЭВ является проблемой клинического уровня, оказывающей негативное влияние на психический статус, социальную адаптацию и качество жизни.

Ключевые слова: синдром эмоционального выгорания, врач-психиатр, профессиональный стресс, эмоциональное напряжение, индивидуальнопсихологические особенности.

\section{Abstract}

The review considers the main theoretical approaches to the burnout syndrome. Most authors believe that the onset of burnout syndrome is a clinical-level problem that has a negative impact on mental status, social adaptation, and quality of life.

Keywords: burnout syndrome, psychiatrist, professional stress, emotional stress, individual psychological characteristics.

Актуальность проблемы синдрома эмоционального выгорания у врачей различных специальностей обусловлена ухудшением как соматического, так и психического здоровья населения. Изучение состояния здоровья у представителей различных социально-профессиональных групп населения, является одной из основных задач медицины [2, 4]. Деформация личности профессионала - одна из наиболее серьезных психологических проблем в современных социально-экономических условиях [1]. По мере профессионализации успешность деятельности начинает определяться набором профессионально важных качеств, которые годами «эксплуатируются». Некоторые из них могут постепенно трансформироваться в профессионально нежелательные качества. Таким образом, становление специалиста, профессионала - это не только совершенствование, но и в каком-то смысле разрушение, деструкция [3].

Существует четыре разновидности теоретических подходов к описанию источников синдрома эмоционального выгорания (СЭВ): индивидуальные, межличностные, организационные и социальные. Индивидуальные подходы обращают особое внимание на роль и процессы внутри личности, в то время как межличностные фокусируются на взаимоотношениях с другими личностями в процессе работы. Организационные подходы делают упор на важность организационного начала, тогда как социальные подходы акцентируются на более широкие социальные и культурные аспекты. Эти четыре разновидности в подходах к проблеме выгорания не являются взаимно исключающими.Авторами подчеркивается необходимость системного подхода к рассмотрению проблемы эмоционального выгорания.

Среди индивидуальных подходов большой интерес представляет концепция Фрюденбергеру и Ричельсона, которые рассматривают синдром выгорания, как модель неспособную сохранить собственное идеализированное самовыражение.

По мнению Фрюденбергеру и Ричельсон [9] выгоранию подвержены «динамичные, харизматичные, целеустремленные мужчины и женщины или устремленные идеалисты». Поэтому этот феномен назвали «болезнью сверхобязательных» или «недугом тех, кто ставит перед собой сверх-задачи». У них 
характерны нереальные или слишком завышенные ожидания, амбиции, ведущие к СЭВ. По Фрюденбергеру и Ричельсон, СЭВ развивается, когда у индивидуума идеализированное представление о себе, как о харизматичной, динамичной, неистощимой, очень компетентной личности. Вследствие чего он полностью теряет контакт с «собственным Я», происходит истощение всех энергетических ресурсов.

Эделвич и Бродски[8] описывают СЭВ, как результат прогрессирующего разочарования.Базовый принцип их модели сводился к тому, что изначальные идеалистические ожидания личности подвержены разрушительным влияниям каждодневных реалий. Авторы полагают, что благородные устремления тяжело реализовать на практике из-за нескольких источников фрустрации в человеческом общении: отсутствия оценки критерия достижений, низкого уровня оплаты труда, слабых перспектив карьерного роста, недостаточной организационной поддержки и низкого общественного статуса. Постепенный прогресс развития СЭВ может происходить по следующим четырем стадиям прогрессирующего разочарования: энтузиазм; застой, фрустрация, апатия.

Мейер [18] полагал, что СЭВ развивается как результат модели ошибочных ожиданий, который не соответствует действительной рабочей ситуации. Существуют три вида таких «ожиданий»: закрепленные ожидания; исходные ожидания; реальные ожидания. В дополнение к этим видам «ожиданий», Мейер ввел понятие «связующего воздействия», подчеркивая, что данные три типа находятся под влиянием индивидуальных и общественных факторов. На ожидания индивидуума также влияют его индивидуальные убеждения и правила общественного поведения.

Бурищ [5] предложил подход к синдрому выгорания, в котором решающее значениепридавалось модели действий. Теория действий рассматривает так называемые эпизоды действия, как базовые элементы анализа. Эпизод ненарушенного действия является циклическим процессом, который начинается, когда латентные мотивы индивидуума активируются. Многое может препятствовать ненарушенному развитию эпизода действий. Бурищ различает четыре вида нарушений, которые могут помешать такому развитию: барьеры в реализации мотива, барьеры в достижении цели; недостаточное вознаграждение, неожиданные негативные побочные эффекты.

В недалеком прошлом новая общая теория стресса, названная Консервацией Ресурсов («КОР» от английского «COR» - ConservationofResources), была использована применительно к синдрому выгорания [12], так называемая, модель потери ресурсов. Теория КОР базируется на том, что люди имеют глубоко укоренившуюся мотивацию приобретать, удерживать и защищать то, что они ценят больше всего. Согласно теории КОР, психологический стресс развивается в ситуациях, когда личностным ресурсам что-то угрожает и прирост ресурсов не соответствует вложенным затратам. Обычно индивидуум эффективно справляется с появляющимся стрессом при помощи распределения ресурсов или инвестиций в них, поэтому так важно создавать резервуар ресурсов. СЭВ формируется тогда, когда осознается, что потеря важных личностных ресурсов не может быть восполнена. Подход КОР к СЭВ исходит из того, что этот процесс самовоспроизводится и что наличие и использование ресурсов является критическим для его развития.

Психоаналитик Фишер [22] рассматривал выгорание, как модель нарциссического расстройства личности. Согласно теории Фишера, те индивидуумы, которые идеализируют свою работу и затем страдают от разочарования, могли бы снизить свою вовлеченность, либо понизить значимость своих идеалов или просто уйти из сложившейся ситуации, тем самым - избежать СЭВ. Если же индивидуум отказывается понизить значимость своих идеалов, а, наоборот, удваивали свои усилия для того, чтобы добиться нереальных целей, развивается СЭВ.

Основываясь на положениях психологии экзистенциализма, Пайнс разработала мотивационный подход к СЭВ, при котором базовая потребность индивидуума к 
поиску значения и смысла жизни играет критическую роль [21]. Согласно ее модели, синдрому выгорания подвергаются только высоко мотивированные личности. Пайнс считает, что СЭВ является конечным результатом постепенного процесса разочарования в стремлении заполучить чувство важности существования от своей работы. Индивиды «сгорают», потому что их опыт не соответствует их намерениям и ожиданиям.

Среди межличностных подходов интересна модель СЭВ - как модель эмоциональной перегрузки, разработанная Маслаш (1993) [15]. По Маслаш СЭВ негативный личный опыт, внедренный в контекст межличностных отношений на работе. Он включает профессиональную концепцию как себя, так и других. Межличностные требования, формирующиеся из отношений взаимопомощи, рассматриваются как основная причина СЭВ. Отношения взаимопомощи несут эмоциональный заряд по своей природе, вследствие чего они представляют сами по себе большую психологическую нагрузку. Для того, чтобы справляться с такими эмоциональными требованиями и эффективно выполнять свою деятельность, профессионал может применять технику отстранения. Таким образом, СЭВ представляет последовательный процесс, который начинается с эмоционального истощения, производного от эмоциональных затрат вследствие общения с клиентами, неудачная попытка купировать эмоциональное истощение ведет к развитию деперсонализации. Из-за применения нефункциональной стратегии купирования, еще сильнее ухудшаются отношения с клиентами, чаще возникает разочарование. Все это постепенно ведет к развитию чувства заниженных личных достижений.

Бунк и Шауфели [6] связывают СЭВ с процессом общественных взаимоотношений на межличностном уровне, как недостаток взаимности. «Дающие» чувствуют, что они продолжают вкладывать в отношения значительно больше, чем они получают обратно. Недостаток взаимности опустошает эмоциональные ресурсы профессионала и ведет к эмоциональному истощению.

А.Хоччайлд [13] при анализе СЭВ выдвинул концепцию эмоциональных усилий. Согласно Хоччайлд, существуют два типа эмоциональных усилий (труда): поверхностное действие; глубокое действие. Оба они могут привести к значительным негативным последствиям. Поверхностное действие демонстрирует эмоции, которые не ощущаются и создает чувство напряженности, которое обозначается эмоциональным диссонансом. Конфликт между действительно переживаемыми эмоциями и эмоциями, которые необходимо продемонстрировать, могут вызвать СЭВ, потому что он опустошает эмоциональные ресурсы личности и вызывает цинизм, отчуждение и отстранение, т.е. деперсонализацию. Глубокое действие может привести к самоотчуждению, так как индивидуум находится в опасности потери связи с собой исполнение роли становится восприятием роли. Т.к. глубокое действие требует излишних затрат энергии, оно может истощить эмоциональные ресурсы личности.

Моррис и Фелдмен [20] полагали, что в дополнение к качественным аспектам модели эмоциональных усилий (эмоциональный диссонанс и самоотчуждение), необходимо учитывать её количественные аспекты: частоту эмоциональных проявлений; внимательность проявлений; изменчивость к правилам их проявления. По Моррису и Фелдмену [20], риск синдрома выгорания усиливается, когда показатели частоты, внимательности и изменчивости высокие, т.к. требуется больше эмоциональных усилий. Другие подходы связывают развитие синдрома выгорания с психологическими процессами(общественные контакты, обмены, дефицит взаимности, эмоциональная «инфекция» или эмоциональные усилия).

В научной литературе представлены три модели организационных подходов к обоснованию СЭВ.В конце 1970-х годов Чернисс [7] путем опроса 26 профессиональных служащих, которые только что приступили к своей деятельности (адвокатов, школьных преподавателей, медицинских сестер и работников 
психиатрических клиник), выявил, что они не смогли найти в своей профессии то, что первоначально ожидали. Их ожидания столкнулись с организационной реальностью и профессионалы стали терять энтузиазм и проявляли выраженную тенденцию психологического отчуждения от сотрудников и от самой работы. В основе модели Чернисс лежат различные стрессоры, которые создаются, в большей части, рабочей обстановкой, и, в меньшей - самой личностью. При активном адекватном решении проблем замедляется процесс истощения, т.к. устраняются его вызывающие причины, в противном случае, негативное отношение становится привычной нормой поведения.

Голимбиевски [10] с коллегами рассматривают СЭВ как «вирулентный процесс», который развивается, проходя через восемь фаз. «Спусковым курком» синдрома эмоционального выгорания выступают стрессоры, связанные с работой, это приводит к появлению физических симптомов, снижению рабочих показателей и падению производительности. Это способствует негативным последствиям не только для конкретной личности, но также и для организации. По Голимбиевски, в отличие от Маслаш, процесс выгорания начинается с деперсонализации, за которой соответственно следуют падение личных достижений и эмоциональное истощение.

Согласно Маслаш и Лейтер [17] СЭВ являетсябуказателем неправильного соотношения между тем, чем являютсябличности, и тем, что им приходится делать. Выгорание возникает в результате хронического дисбаланса, вбкотором работа требует больше, чем работодатель может предоставить,би обеспечивает меньше, чем работающему необходимо. СЭВ рассматривается как специфический аспект несоответствия личности с работой.

Среди социальных подходов к выгоранию популярна модель отчуждения. Каргер [14] полагал, что существует сходство между выгоранием и индустриальным отчуждением, как это было описано Карлом Марксом свыше ста лет тому назад. Отчуждение похоже на современную характеристику СЭВ, включая истощение и деперсонализацию. По марксистской терминологии, выгорание происходит от «овеществления» способов производства профессионала, т.е. общественные и межличностные навыки профессионала становятся рыночным товаром. В организациях, работающих в социальных службах, овеществление имеет место между личностью и личностью и, таким образом, способствует деперсонализации. Иначе говоря, их работа теряет личностное значение, когда она становится просто товаром для рынка. Овеществление ведет к другим негативным последствиям, которые могут способствовать возникновению процесса выгорания, таким как фрагментация работы, конкуренция среди коллег и потеря автономности.

Хэнди [11] рассматривала синдром выгорания, как модель несоответствия между поверхностными и скрытыми функциями организации.

Работы Мейерсона [19] направлялись на то, чтобы оценить социальную конструкцию СЭВ. Она изучала две учрежденческие системы, которые встречаются среди социальных работников в госпиталях: медицинскую модель и психосоциальную модель. В медицинской модели СЭВ рассматривался как патологическое состояние здоровья, которое нужно было держать под контролем, как болезнь. Там, где преобладала психосоциальная модель, СЭВ считался социальной проблемой и нормальной частью работы и выступал не как личный или профессиональный недостаток, а неизбежный случай и нормальная часть работы. СЭВ является самовоспроизводимым процессом: присутствие (или отсутствие) СЭВ усиливает ту самую культуру, которая его порождает (или не порождает). Описана переходная или диалектическая природа СЭВ - служащие считаются не пассивными жертвами, а активными участниками процесса, которые индивидуально и коллективно формируют свое рабочее и жилое пространство, которое может содействовать (или не содействовать) возникновению СЭВ. 
Существует большое количество теорий СЭВ. Ни один теоретический подход не в состоянии объяснить сложность взаимодействия комплекса СЭВ с многочисленными аспектами. Каждое теоретическое объяснение выгорания остается фрагментарным, частичным. В.Шауфели и Д.Ензманн предпринимают попытку объединить общие моменты, которые встречаются в нескольких подходах. Они предлагают интегративную и описательную модель СЭВ, которая схематически суммирует общие моменты, присутствовавшие в предыдущих подходах [23].

Таким образом, три повторяющиеся темы проходят через многие подходы: сильная начальная мотивация является необходимым условием для развития выгорания, СЭВ ассоциируется с неблагоприятным рабочим окружением, процесс развития СЭВ само воспроизводимый, поскольку используются неадекватные техники купирования. СЭВ затрудняет профессионалу достижения его целей, опустошает ресурсы купирования - «петля потери, но с позитивной точки зрения, эффективность работы профессионала увеличивается, когда цели достигнуты и ресурсы купирования пополнены - «петля достижений».

$$
* * *
$$

1. Абдуллаева, М. М. Профессиональная идентичность личности: психосемантиче-ский подход / М. М. Абдуллаева // Психологический журнал. - 2004. - Т. 25, № 2. - С. 86-95.

2. Дмитриева, Т. Д. Социальная психиатрия: современные представления и пер-спективы развития / Т. Д. Дмитриева, Б. С. Положий // Обозрение психиатрии и медицинской психологии им. В. М. Бехтерева. - 1994. - № 2. - С. 39-49.

3. Зеер, Э. Ф. Психология профессий: учебное пособие для вузов / Э. Ф. Зеер. - 2-е изд., перераб. и доп. - Москва ; Екатеринбург : Академический проект : Дело-вая книга, 2003. - 330 с. : ил. (Gaudeamus).

4. Социальный стресс и психическое здоровье / Т. Б. Дмитриева, А. И. Воложин, Ю. А. Александровский [и др.] ; под ред. Т. Б. Дмитриевой, А. И. Воложина. - Москва : ВУНМЦ, 2001. 249 c.

5. Burisch M. In search of theory: some ruminations on the nature and etiology of burnout. In Professional Burnout: Recent Developments in Theory and Reseatch ed./W.B.Schaufeli, C.Maslach and T.Marek // Washington, DC: Taylor \&Francis. - 1993, P.75-93.

6. Buunk B.P. Burnout: A perspective from social comparison theory. Professional burnout: recent developments in the theory and research. / B.P. Buunk, W.B. Shau-feli, Cr. Maslach\& T. Marek// Washington D.C.: Talor\& Francis, 1993, p. 53-69.

7. Cherniss C. Professional Burnout in the Human Service Organization/ C. Cherniss. - New York: Praeger. 1980. - 295 p.

8. EdelwichE. Stages of Disillusionment in the Helping Professions / E.Edelwich, A.Brodsky- N. Y., 1980. $-255 \mathrm{p}$.

9. Freudenberger, H.J. Burn-out: How to Beat the High Cost of Success / H.J.Freudenberger, G.Richelson, New York: Bantam Books, 1980. - 259 p.

10. Golembievski R.T. Burnout has also gone global, it seems: Mounting worldwide evidence based on the phase model. Current topics in mangement./ M.A.Rahim (Ed.), R.T. Golembievski (Ed.) et al. Jai Press, Inc. Greenwich, CT, USA, 1997, Vol. 2, p. 45-60.

11. Handy, J.A. Theoretical and methodological problems within occupational stress and burnout research. / J.A. Handy, - Human Relations, Vol. 41, p. 351 - 369.

12. Hobfoll S. Conservation of resources: A general stress theory applied to burnout /S.Hobfoll, J.Freedy, W. Schaufeli, C. Maslash, T. Marek (eds) // Professional burn-out: Recent developments in theory and research. Washington, DC: Taylor \& Fran-cis, 1993. P. 115-129.

13. Hochschild, A.R.The Menagel Heart /A.R.Hochschild//Commercialization of Human Feeling Berkeley CA: University of California Press, 1983.

14. Karger, H.J. (1981) Burnout as alienation / H.J. Karger // Social Service Review, 55, 270 - 283.

15. Maslach C. Burnout: A multidimensional perspective / Professional burnout: Recent developments in the theory and research. / Ed. W.B. Shaufeli, Cr. Maslach\& T. Marek, Washington DC: Taylor \& Francis, 1993, P. 19-32.

16. Maslach C. Job burnout / C.Maslach, W.B.Schaufeli,M.P. Leiter// In: Fink S.T., Scheter D.L., Zahn Waxier C., editor // Annual Review of Psychology, 2001, Vol.52, P.397-422.

17. Maslach $\mathrm{C}$. The truth about burnout: How organization cause personal stress and what to do about it $/ \mathrm{C}$ .Maslach, M.P.Leiter, - San Francisco, CA. Jossey-Bass, $1997-186$ p.

18. Meier S.T. Toward a theory of burnout / S.T. Meier // Human Relations. 1983; 36, P.899-910. 
19. Meyersen D.E. Feeling stressed and burnout: A feminist reading and revisioning of stress-based emotions within medicine and organization science / D.E. Meyersen// Organization Science, 1998, Vol. 9 (1), p. 103-110.

20. Morris,J.A. (1996) The dimensions, antecedents, and consequences of emotional labor / J.A. Morris and D.C. Feldman // Academy of Management Revier, 21, 986-1010.

21. Pines A.M. Burnout: An existential perspective / A.M. Pines // Professional burn-out: recent developments in the theory and research/ Ed. W.B. Shaufeli, Cr. Maslach\& T. Marek, Washington DC: Taylor \& Francis, 1991, p. 33-51.

22. Pfeiffer, R. (1983) Early adult development in the medical student. Mayo Clinic Proceedings, 58, 127134.

23. Schaufeli W.B. The burnout companion to Study \& Practice: A critical analysis / W.B.Schaufeli, D.Enzmann,W.B.Schaufeli, D.Enzmann// Printed by T.J.International Ltd, Padstow, UK, 1998, 220 p.

24. Schaufeli W.B. ( 1996b) Burnout and reciprocity: Towards a dual-level social ex-change model / W.B. Schaufeli, et al // Work\&Stress, 3, 225-237.

Галстян Н.В.

Внутриаптечный контроль лекарственных препаратов

Северо-Осетинский государственный университет имени К.Л Хетагурова (Россия, Владикавказ)

doi: $10.18411 / \mathrm{j}-05-2021-43$

\section{Аннотация}

В настоящее время довольно стремительно растет производственная деятельность аптечных организаций, с каждым днем появляются новые и новые лекарственные препараты, совершенствуется технология изготовления, но все же вместе с таким развитием фармацевтической сферы на рынок до сих пор выпускается довольно большое количество некачественной лекарственной продукции, выпускаются некачественно изготовленные, фальсифицированные препараты, которые не соответствуют сроку годности и правилам хранения.

Несмотря на то, что большинство и основополагающее число лекарственных препаратов производится заводами, все же остается небольшое количество, которое требует внутриаптечного изготовления. Данная востребованность обусловлена множеством факторов: возможность медицинского работника подобрать более индивидуальный состав, а также дозировку для пациента с учетом индивидуальных особенностей, таких как вес, возраст, наличие сопутствующих заболеваний; изготовление лекарственного препарата в более короткие сроки между датой назначения, процесса изготовления и началом применения; и возможное отсутствие использования консервантов, что также является весьма важным фактором.

Ключевые слова: производственная деятельность, технология, препараты, продукция, востребованность.

\section{Abstract}

Currently, the production activity of pharmacy organizations is growing quite rapidly, new and new drugs appear every day, the manufacturing technology is being improved, but nevertheless, along with such a development of the pharmaceutical sector, a rather large number of low-quality drug products are still being produced on the market, and poorly manufactured, counterfeit drugs that do not meet the expiration date and storage rules.

Despite the fact that most and most of the drugs are manufactured in factories, there is still a small amount that requires intra-pharmacy production. This demand is due to many factors: the ability of a medical worker to choose a more individual composition, as well as a dosage for a patient, taking into account individual characteristics, such as weight, age, the presence of concomitant diseases; manufacturing of a medicinal product in a shorter time period between the date of appointment, manufacturing process and the start of use; and the possible absence of the use of preservatives, which is also a very important factor.

Keywords: production activity, technology, drugs, products, demand. 